\title{
VIAJANDO EM NOVAS HISTÓRIAS
}

\author{
Entrevista de Maria Gabriela Mantaut Leifert com Cristina Ruffino
}

sta entrevista foi realizada por meio de um bate-papo por Skype no dia 12 de abril de 2019. Visa à apresentação do trabalho desenvolvido em uma Escola Municipal de Ensino Fundamental de Ribeirão Preto que pediu auxílio para tratar de um tema muito recorrente na atualidade: adolescentes que estão em situação de risco, apresentando sintomas de depressão, praticando automutilações e com ideações suicidas ou histórico de tentativa de suicídio.

A adolescência é uma fase de muitas mudanças no âmbito do corpo físico, psicológico e social. Nos últimos anos, observa-se um crescimento no número de adolescentes sofrendo de tristeza extrema e que praticam a automutilação como recurso de alívio para suas dores. Cris Ruffino conversa conosco fornecendo pistas valiosas de sua experiência junto a estes adolescentes. Tive um imenso prazer em ouvir sua narrativa, principalmente pela sua grande empatia com esta faixa etária e sua enorme disposição em promover encontros afetivos dentro de situações de extrema vulnerabilidade e sofrimento.

Entrevistadora - Como você se envolveu com este trabalho? Como ele surgiu?

Cris - Desde que nasceu, em 2007, o ConversAções desenvolve atividades de cunho social na forma de trabalho voluntário junto à comunidade, órgãos públicos e do terceiro setor. Foi este histórico de trabalhos sociais que levou a coordenadora de uma escola municipal de ensino fundamental a me procurar para solicitar ajuda com alguns alunos que apresentavam comportamentos preocupantes para a escola ou que solicitaram ajuda. Alguns apresentavam traços preocupantes de estados depressivos, praticavam autolesões, referiam a ideações suicidas e, inclusive, havia ocorrido uma tentativa de suicídio recente. A coordenadora da escola naquela ocasião era a pedagoga Sandra Lamas, que é uma profissional muito envolvida e dedicada com formação em Terapia Comunitária com o Adalberto Barreto. Ela vinha desenvolvendo trabalhos nesta linha com os adolescentes, mas entendia que poderia ser desenvolvido algo mais. Foi então que me procurou, perguntando o que seria possível desenvolver na escola com aqueles adolescentes.

\section{Entrevistadora - Como foi esta aproximação?}

Cris - Como sempre fazemos, primeiro ouvi o pedido da escola, representada pela coordenadora, diretora e vice-diretor para entender qual era o problema para eles, o que já havia sido feito, quais os resultados que já tinham conseguido. Ao seguir esta conversa com eles, vi que já vinham dedicando atenção e empenho à questão, me solidarizei com todo o esforço já feito e fiquei de apresentar um projeto. Uma possibilidade que me pareceu interessante seria utilizar as Práticas Narrativas Coletivas, como proposta por Denborough, no trabalho com os adolescentes,

\section{CRISTINA RUFFINO}

\section{MARIA GABRIELA MANTAUT LEIFERT ${ }^{2}$}

${ }^{1}$ ConversAções Instituto de Facilitação de Diálogos, Ribeirão Preto/SP, Brasil

${ }^{2}$ (Entrevistadora) Instituto Noos, São Paulo/SP, Brasil 
pensando que eles poderiam vir a ser multiplicadores com outros adolescentes. Compartilhando a ideia com a Laura Vilela, professora da USP, ela se interessou em inserir na questão duas alunas que estavam trabalhando com o tema em contato. Assim eu, juntamente com a mestranda Camila Martins Lion e a aluna de iniciação científica Aglaia Ruffino Jalles, construímos um projeto para desenvolver com estes jovens na escola.

Entrevistadora - Então, Cris,como foram os encontros?

Cris - Uma vez o projeto aprovado pela escola, começamos a conversar com os adolescentes para compreender o que, no entendimento deles, estava acontecendo e que pedido teriam. Contamos para eles as nossas ideias iniciais para um trabalho em grupo, que seriam 8 (oito) encontros de duas horas, explicamos todas as implicações e limites para a participação e a voluntariedade da participação deles, a necessidade da aprovação dos pais na participação e da assinatura do Termo de Consentimento Livre e Esclarecido. Foi negociado com os adolescentes de que forma apresentar o projeto para os pais e qual deles preferia estar presente na conversa que foi feita individualmente com o responsável de cada adolescente pela Camila Lion.

Os adolescentes também foram consultados sobre a possível participação da coordenadora da escola neste trabalho, já que ela vinha trabalhando com eles em terapia comunitária até então. Alguns demostraram interesse na participação dela, outros ambivalência e outros preferiam que não, por ser alguém que identificavam como sendo da escola e entendiam que neste grupo se sentiriam mais à vontade para falar de si, incluindo questões envolvendo relações dentro da escola, se não tivesse nenhum profissional da escola no grupo. Dessa forma, o grupo foi composto só por nós três, proponentes do Projeto, que não estávamos identificadas por eles como profissionais da escola, e os adolescentes.

A equipe da escola foi muito acolhedora, entendeu nossas condições e nos deu todo apoio para o trabalho. Formamos um grupo inicial de 12 alunos interessados em participar voluntariamente. A escola nos disponibilizou o espaço da biblioteca duas vezes por semana, das 13:00 às 15:00. Tivemos a liberdade de ajustar o espaço às necessidades do grupo.

Entrevistadora - Quais eram as principais questões?

Cris - Das questões que eles traziam na entrevista individual apareciam muitas relativas a gênero, sexualidade, relações amorosas e amizades; também apareceram muitas dificuldades com a família pela não aprovação das suas escolhas, modos de vida, amigos e namoros; além das questões ligadas à adesão à automutilação como uma forma de alívio para o sofrimento. Também apareceu na fala de alguns a questão de pensarem no suicídio ou já terem tentado.

Entrevistadora - Qual foi o aporte teórico deste trabalho e como se deram os encontros?

Cris - A inspiração para este trabalho foram as práticas narrativas coletivas desenvolvidas por David Denborough, as leituras na NPS dos trabalhos da Lúcia Helena Abdalla, da Adriana Müller e de outras colegas que desenvolveram lindos trabalhos com estes princípios e recursos. Este era o tema de estudo da Camila 
e da Aglaia. Eu já tinha uma certa experiência de uso de alguns recursos em outros contextos, mas desejava desenvolver um trabalho mais consistente. Somamos nossos interesses, ideias e esforços para o trabalho.

Começamos a trabalhar a partir da metáfora de viagem. Propusemos a eles: "Vamos construir uma viagem para que a gente possa conhecer a nós mesmos?". A Camila e a Aglaia, muito caprichosas, construíram malinhas e, ali, cada um poderia colocar ao longo dos encontros suas produções. Fizemos também um compartimento em cada mala onde os demais poderiam deixar bilhetes, recados apreciativos ou bons votos para o dono da bagagem. Sabíamos que nós três éramos temporárias na escola, mas eles provavelmente seguiriam juntos por mais tempo. Daí nosso esforço em oferecer recursos que os ajudassem a criar ou fortalecer vínculos entre eles.

Uma das primeiras coisas que percebemos foi que, para criar um ambiente gostoso, seria importante termos outras opções além das mesas e cadeiras. Levamos tapetes de yoga, cangas, pranchetas, bonecos, formamos um centro com objetos de fala e um enfeite e oferecemos a opção de sentarem no chão. Opção que foi acatada por todos. Foi muito interessante como encontrar um espaço produzido de forma a convidar para uma aproximação e acolhimento teve um efeito imediato neles. Eles passaram a sugerir outras possibilidades e como implementar melhor o espaço. Nosso miniuniverso foi ganhando novas cores com a ajuda deles.

Entrevistadora - E como vocês conseguiram os materiais para a construção da sala?

Cris - Fizemos uma campanha pelo facebook entre os conhecidos, pedimos para os amigos, alunos do ConversAções, enfim, muitos ajudaram de forma muito generosa. Recebemos: almofadas, canetinhas, papéis e uma boneca da Frida Kahlo que fez muito sucesso entre eles, virando ícone. Esta é uma parte que me emociona bastante: ver como as pessoas estão dispostas a contribuir e a oferecer. Rapidamente juntamos tudo. Conseguimos alguns bichos de pelúcia e eles também começaram a levar os deles. Interessante como se identificavam com os bichos, abraçavam e faziam as atividades com os bonecos no colo. Adolescentes, com a vida sexual ativa, vivendo muitas coisas de um universo adulto, apresentavam, ao mesmo tempo, uma meiguice quase infantil do "meu ursinho", "minha Frida". Isto tudo foi muito bonito, foram passando do abraço do ursinho, para o abraço no amigo e amiga.

Entrevistadora - Quais os aprendizados e mudanças que você e sua equipe perceberam?

Cris - Uma coisa que me chamou atenção é que o contato físico entre os adolescentes neste contexto muitas vezes era: ou sexualizado ou agressivo ou de evitação. Ali eles foram construindo uma outra forma de estarem juntos. Era possível deitar no colo um do outro, abraçar quando choravam, fazer cafuné, darem abraços coletivos, enfim, aproximações pelo afeto amigo, vivenciar relações de acolhimento mesmo. Isso foi, para alguns, muito novo.

Nós iniciamos o projeto oferecendo a metáfora da viagem, mas no decorrer do trabalho vimos que outras metáforas e recursos eram trazidos e tomavam corpo, por exemplo, a música. Percebemos que eles usavam as músicas que ouviam para expressarem e falarem de si. Foram nos apresentando suas músi- 
cas preferidas e a partir delas falavam da vida e da vivência deles. Escreveram muito, desenharam.

Nós aprendemos muito com eles, o tempo todo. Por exemplo, fomos com a ideia tradicional de eles escreverem em papel e descobrimos que alguns preferiam escrever pelo WhatsApp e que este era um recurso válido para expressão também. Mandavam-nos textos longos, com narrativas coordenadas e emocionadas, falavam do que viviam, várias coisas difíceis da vida deles, abusos que tinham sofrido, violências vividas e presenciadas, tudo com a linguagem e com o recurso que é mais próximo da realidade deles. No decorrer dos encontros fomos conhecendo melhor cada um, alguns se conheciam e eram "inimigos", alguns se conheciam e eram amigos e outros não se conheciam. Houve momentos de estresse e momentos de muita tensão entre eles; foi necessário negociar diferenças e ouvir o outro. Houve choros e risadas, estranhamentos e abraços.

Entrevistadora - Qual foi o processo que vocês usaram para tentar ajudá-los?

Cris - Foi necessário criar um contexto onde todos podiam conversar, trazer suas narrativas de vida, de sofrimentos, de superações. Ao escutá-los, ajudávamos a identificar e destacar as habilidades de que dispunham, os recursos que utilizaram para lidar com aquelas histórias, quais foram os movimentos de proteção, onde e em quem foram encontrando apoio, quais os sonhos e esperanças, que valores os sustentavam. Eles foram demonstrando a preocupação e o desejo de ajudar outras pessoas que vivenciavam dores parecidas com as deles. Conversavam sobre como ajudar outros amigos ou conhecidos da internet. O desejo de ajudarem outros era compartilhado no grupo. Não desejavam que outros passassem pelo que eles próprios passaram. Um dia um trouxe a história de uma amiga virtual que estava mal e todos gravaram áudio para ela dando apoio, ideias de como melhorar. O desejo de partilhar era grande.

Entrevistadora - Como surgiu a ideia de compor uma música e fazer uma cartilha?

Cris - Primeiro veio a ideia de fazer uma cartilha com sugestões de como lidar com a falta de expectativa e sentido na vida. Essa ideia foi trazida por um participante que tinha tentado suicídio. Nós não tínhamos ideia clara de como viabilizar este projeto, mas achamos interessante e fomos estimulando o trabalho deles. Como trabalhamos muito com as músicas com que eles se identificavam e eles escreviam de si a partir das músicas, apareceram coisas muito poéticas, muito bonitas e acabou surgindo a ideia de criarem uma música com a fala de todos de forma a partilhar suas histórias e os recursos que encontraram. Eles sempre colocavam o foco em ajudar outros adolescentes.

Quando contaram da música, falei com um dos membros de uma banda que já havia recorrido ao serviço social do ConversAções e, portanto, nos conhecia. Essa banda é muito reconhecida em Ribeirão Preto, é formada por três irmãos (João Paulo, Antônio e Pedro Barrionovo) e chama Kilotones. Contei que estava trabalhando com um grupo de adolescentes e os mesmos queriam fazer uma música e eu não tinha a menor ideia em como ajudá-los. Um dos membros da banda se encantou com a iniciativa dos adolescentes e prontamente se disponibilizou para ajudar. Saber do interesse da banda foi algo que os adolescentes escutaram com um misto de surpresa e descrença. Os músicos foram muito habilidosos em 
buscar com os adolescentes os sentidos de cada frase que havia na poesia inicial, contaram da sua própria história e de como tiveram que vencer obstáculos para construir o que acreditavam. Foi uma aula de vida.

O mesmo se deu com a produção da cartilha. Procurei um jornalista, arquiteto urbanista, quadrinista e editor do selo alternativo de quadrinhos RPHQ, o Cordeiro de Sá. Cordeiro tem experiência em edição e financiamento coletivo. Ele foi extremamente receptivo e se prontificou a ajudar, ofereceu oficinas de narrativa para a turma e está editando o livro e produzindo o vídeo para o financiamento coletivo pelo Catarse. O Cordeiro, além de contribuir com a expertise técnica, demonstrou um interesse real em conhecer a vida deles, ouvir as histórias, saber das questões de gênero. Os adolescentes ficaram surpresos em saber que tinham pessoas interessadas e se importando com suas histórias de vida, de como se sentiam, como lidavam com as questões de gênero, as dificuldades que encontravam, as alegrias, enfim, se interessavam por eles como pessoas.

Os encontros na escola foram somente até o final do ano letivo de 2017, mas continuamos com encontros esporádicos no decorrer de 2018 e 2019 na sede do ConversAções para as oficinas de narrativa e música. O bairro em que moram os adolescentes é distante, eles não podiam usar os passes de ônibus escolar pelo fato de os encontros acontecerem aos sábados, então montávamos uma logística complicada de colher as autorizações com os pais, buscá-los e levá-los de volta. Agora, em 2019, a banda gravou a música que compôs com inspiração nas conversas e versos deles, que foram chamados para participar da gravação. Todas as vozes dos que puderam e quiseram participar foram incluídas. Reconheço que os músicos fizeram um trabalho genial com eles. Para os jovens, conhecerem e estarem em um estúdio, gravarem e se escutarem foi um evento especial.

Vivemos de uma forma intensa com esses adolescentes, tivemos muito prazer em ver o que foi acontecendo com eles no decorrer dos encontros e, ao mesmo tempo, uma certa tristeza em saber que não conseguiríamos mantê-los juntos por mais tempo.

Entrevistadora - Vocês conseguiram um outro tipo de suporte para esses adolescentes?

Cris - A maioria já saiu daquela escola, foi para escolas diversas. Poucos ainda se encontram. Mas os jovens puderam se cuidar por muito tempo, formaram uma rede de cuidado entre eles. Acredito que ficaram sementes.

Tentamos encontrar apoio em serviços públicos onde eles poderiam buscar ajuda; nem todos conseguiram. Alguns conseguiram desenvolver com a família um contexto de conversa no qual a família foi entendendo que há escolas que acolherão melhor, outras não. Algumas famílias compreenderam as questões de gênero, outras ainda têm dificuldade em lidar com isto, acham que é a falta de Deus.

Entrevistadora - Mas com certeza eles sabem que podem procurar vocês quando precisarem.

Cris - Sim, ainda nos procuram em momentos de dificuldade e o WhatsApp é um grande aliado nisso. Vamos tentando manter o contato e as possibilidades. A música será lançada em setembro, nos eventos do Setembro Amarelo (mês de prevenção ao suicídio) e a cartilha para impressão será feita com financiamento 
coletivo; estamos nos detalhes finais. Eles ainda não confiam muito, às vezes ficam descrentes de que acontecerá, são coisas muito fora do universo conhecido de cada um. Tenho que confessar que, para mim, também é novo incluir música e edição de cartilha. Mas há momentos em que isso se ilumina e os jovens veem aquilo como uma possibilidade, algo lindo!

No fim de um encontro em 2018, um nos disse: "Nossa, vocês não desistem da gente!”. E eu fiquei pensando que é uma população que já viu tantos serviços e pessoas desistindo deles e das próprias famílias. Fico imaginando de quantas famílias nossa sociedade já desistiu faz tempo. O desafio é como mudar esta realidade.

\section{REFERÊNCIAS}

Denborough, D. (2017). Práticas narrativas coletivas. Trabalhando com indivíduos grupos e comunidades que vivenciaram traumas. South Australia: Dulwich Centre Publications. Trad. Adriana Muller, Roberto Dias, Viviane A. de Oliveira.

\section{CRISTINA RUFFINO}

Pedagoga, doutora em Psicologia pela USP/RP e mestre em Psicologia da Educação pela UNICAMP. Terapeuta de família e de casal e mediadora de conflitos, ambas as certificações pelo Instituto Familiae/RP. Cofundadora do ConversAções Instituto de Facilitação de Diálogos, RP, onde cocoordena o curso de Terapia Familiar e de Casal.

E-mail: cristina@conversacoes.com.br

\section{MARIA GABRIELA MANTAUT LEIFERT}

Psicóloga, terapeuta de casal, família e mediadora vinculada à equipe de gestão do Instituto Noos.

Email: mgmleifert@gmail.com 